This item was submitted to Loughborough's Research Repository by the author.

Items in Figshare are protected by copyright, with all rights reserved, unless otherwise indicated.

\title{
Process repeatability and sources of error in indirect SLS of aluminium
}

PLEASE CITE THE PUBLISHED VERSION

PUBLISHER

(C) Emerald Group Publishing Limited

LICENCE

CC BY-NC-ND 4.0

\section{REPOSITORY RECORD}

Hopkinson, Neil, and Tim B. Sercombe. 2019. "Process Repeatability and Sources of Error in Indirect SLS of Aluminium". figshare. https://hdl.handle.net/2134/3362. 
This item was submitted to Loughborough's Institutional Repository by the author and is made available under the following Creative Commons Licence conditions.

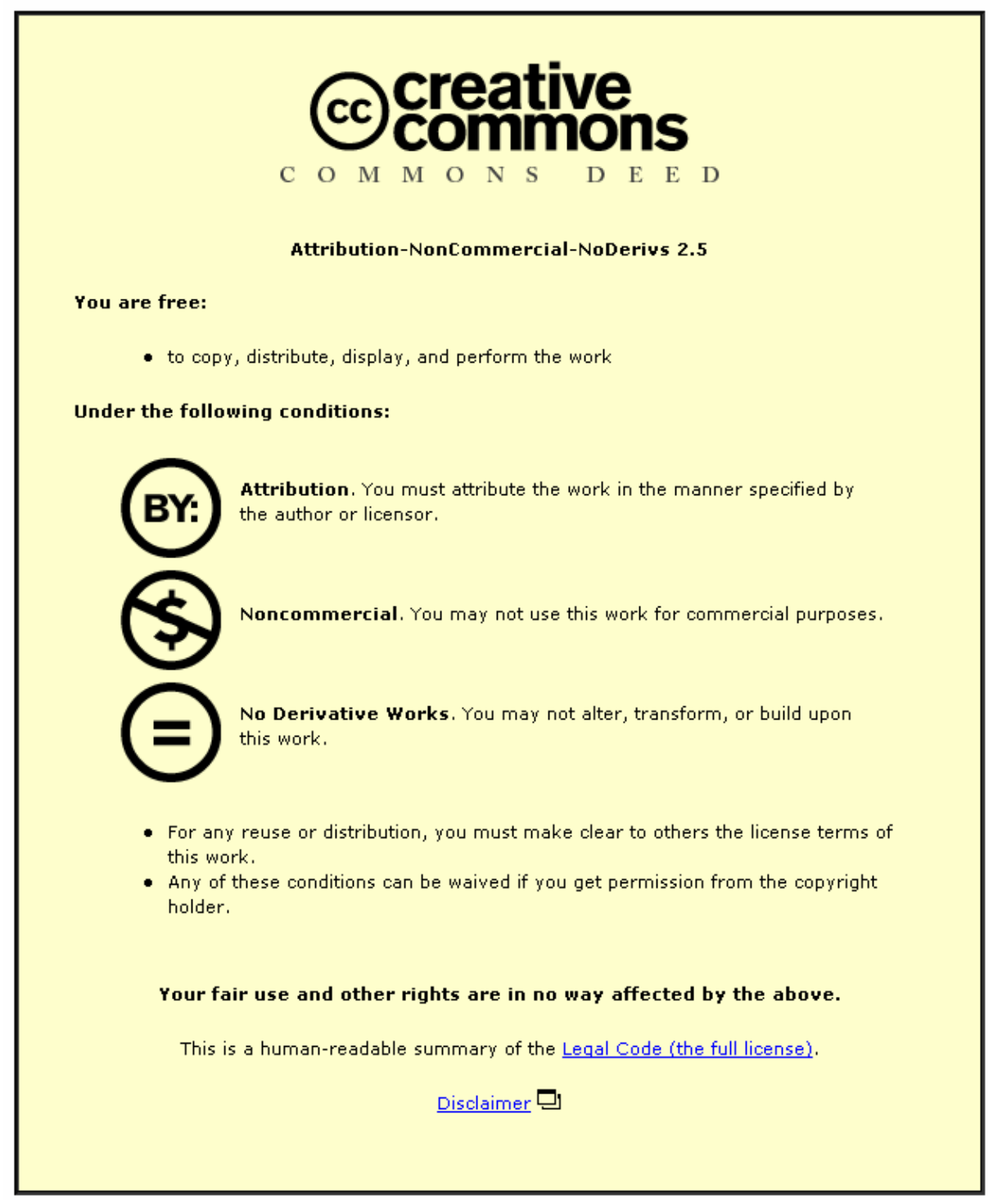

For the full text of this licence, please go to: http://creativecommons.org/licenses/by-nc-nd/2.5/ 


\title{
Process repeatability and sources of error in indirect SLS of aluminium
}

\author{
Dr Neil HOPKINSON \\ Loughborough University, UK
}

Dr T.B. SERCOMBE

Formally, The Division of Materials, School of Engineering, The University of Queensland, St Lucia, Australia, 4072. Now at The School of Mechanical Engineering, The University of Western Australia, Crawley, Australia, 6009 .
Abstract
Purpose - This paper investigates the accuracy and repeatability of the indirect selective laser sintering of aluminium process.
Design/Methodology/Approach - In this paper we characterised the shrinkage of indirect SLS aluminium parts during the various stages of production. Standard scale parts were measured using a Giddings and Lewis co-ordinate measuring machine in both the green and infiltrated condition.
Findings - The conducted experiments show that the most accuracy is lost during furnace cycle and that the greatest loss of accuracy occurred in the $\mathrm{Z}$ dimensions. Additionally the position of parts within the part bed in both $\mathrm{X}, \mathrm{Y}$ and $\mathrm{Z}$ is shown to influence accuracy, with smaller parts being built closer to the edge of the bed later in the build. These results have been interpreted as being a result of the phenomenon of "Z-growth”. Finally the research shows that the overall accuracy of the indirect selective laser sintering of aluminium process is comparable with many existing processes such as investment casting.
Originality/Value - Before any new material can be accepted, there is a need to not only fully characterise the dimensional accuracy attainable, but gain a though understanding of the processes that contribute to the inaccuracies. This paper addresses this need. 
Keywords: Selective Laser Sintering, aluminium powder, process accuracy, repeatability

Paper type Research paper

\section{Introduction}

Despite being in its infancy, rapid manufacturing (RM) is becoming accepted across a diverse group of industry sectors including automotive, medical and aerospace. However as it begins to emerge from behind rapid prototyping and rapid tooling, it faces more stringent investigation, especially with regard to accuracy, repeatability, mechanical properties and part quality issues. Of the many layer-based manufacturing technologies, selective laser sintering is emerging as the leading RM process - especially for plastics and more recently for metals. Being a particulate based process, the accuracy and surface finish is controlled to some extent by the particle size. A given particle is either contained within the build envelope or not, setting limits to the achievable accuracies and surface finishes. In addition to this inherent limitation, shrinkage during laser processing or subsequent thermal post processing can also lead to loss of dimension accuracy. As such, selective laser sintering of polymeric components (such as 3D system's Duraform ${ }^{\mathrm{TM}}$ ), which undergo an in-process contraction of $3-4 \%$ have dimension accuracy significantly worse than stereolithography [2], which is generally considered to be the most accurate of these layer manufacturing processes.

Indirect SLS systems are those in which a resin-bonded ("green”) preform is first produced. This then undergoes a subsequent furnace cycle which is aimed at increasing the parts density, usually through infiltration. Hence, the use of this technique increases the sources of error and consequently one would expect poorer dimensional tolerances. Steel parts, produced using this indirect method, have been available from 3D Systems since the mid 1990's. Studies on 
dimensional accuracy have shown that tolerances of $\pm 0.25 \mathrm{~mm}$ [3] are possible on tooling, with parts produced from tooling have $90 \%$ of dimensions within $\pm 0.25 \mathrm{~mm}$ [4]. This accuracy is superior to what is typically achievable via sand casting $( \pm 0.8 \mathrm{~mm}$ for dimensions between 25 and $175 \mathrm{~mm})$ and investment casting ( $\pm 0.4 \mathrm{~mm}$ for $75 \mathrm{~mm}$ sections), and is similar to that of die-castings $( \pm 0.25 \mathrm{~mm})$ [5]. However, it is inferior to that of machining.

A recently developed [1] indirect method for the production of aluminium components has undergone a brief accuracy analysis [6]. However, this work did not fully explore accuracy and repeatability issues of this system. Hence, in this paper we explore these issues more fully, including an assessment of the effect of part position (in $\mathrm{X}, \mathrm{Y}$ and $\mathrm{Z}$ ) and break down of the error budget to determine the process step that causes the majority of the inaccuracy.

\section{Methodology}

A standard accuracy part, shown in Figure 1(a), was used to generate most of the data for this research. The part comprises numerous stair steps allowing for multiple measurements in X, $\mathrm{Y}$ and Z. Figure 1(a) also indicates positions where measurements in the $\mathrm{Z}$ direction were taken from up facing and down facing surfaces. The part also incorporates a container, into which a block of aluminium infiltrant was placed. A vertical pillar part (see Figure 1(b)) was used to measure effects of build height on dimensions.

All parts were built on a SinterStation $2500^{\text {plus }}$ SLS machine using parameters shown in Table 1. No scale factors or offsets were applied to the STL files as the aim of this research was to identify the repeatability and sources of error rather than the absolute accuracies possible. 
Initially nine parts were built in a 3x3 grid as shown in Figure 2. The base powder used in this work consisted of pre-alloyed AA6061 powder that was mixed with 2\% Mg, 1\% Sn and 3\% (7.5v\%) nylon. All compositions are in weight percent.

After building on the SLS machine, parts were cleaned of loose powder and measured on a Giddings and Lewis model RS-30DCC co-ordinate measuring machine (CMM) to record green dimensions. Next, the parts were spray coated in Boron Nitride and subjected to the furnace cycle shown schematically in Figure 3. This cycle can be divided into four stages: Stage 1 to thermally decompose the nylon binder; Stage 2 to create an aluminium nitride skeleton, Stage 3 to infiltrate with aluminium and Stage 4 cool down. After the furnace cycle, the dimensions of the pars were re-measured using CMM.

\section{Initial Assessment of Dimensional Repeatability using 9 Accuracy Test Parts}

The results presented in this section have been organised to consider accuracy issues in different directions. Results for dimensions parallel to the build bed ( $\mathrm{X}$ and $\mathrm{Y}$ directions) are considered together as they exhibit similarities in behaviour. Results from the $\mathrm{z}$ direction have been split into $\mathrm{Z}_{\text {top-top }}$ and $\mathrm{Z}_{\text {top-bottom }}$ as the issues affecting the two dimensions are different. Dimensions from green parts and infiltrated parts are shown together, so that the effects of the different stages of processing on dimensions can be easily explained. Each Figure shows dimensional data for all 9 parts built in a single run.

\subsection{Dimensions parallel to the build platform}

Figure 4(a) is a plot of the measured error (from nominal size) against nominal dimension for dimensions in the Y direction for both green and infiltrated parts. It can be clearly seen than 
all dimensions in the green state are greater than nominal (ie. greater than the CAD dimensions) with a slight trend for the smaller dimensions to be more oversized. In contrast, the infiltrated dimensions show a marked trend for larger than nominal measurements at smaller dimensions and smaller than nominal measurements at larger dimensions. The consistent slope of data for infiltrated parts indicates a linear shrinkage of $~ 1 \%$ during the furnace cycle. The scatter in measurements for both green and infiltrated parts is reasonably consistent at $\sim \pm 0.15 \mathrm{~mm}$. Similar results were obtained for dimensions in the $\mathrm{X}$ direction.

\subsection{Dimensions in the build direction}

Figure 4(b) shows the error from nominal plotted against nominal for $\mathrm{Z}_{\text {top-bottom }}$ dimensions measured on the Y-face of the test part. As with the Y dimensions shown in Figure 4(a), all green measurements are greater than the nominal, however in this case there is a slight trend for lower errors at smaller dimensions. Also similar to the result shown in Figure 4(a) is the observation that the infiltrated dimensions decrease with increasing nominal size. Again, indicating a linear shrinkage of $\sim 1 \%$ during the furnace cycle. The range of values measured on the green parts remains relatively constant at $\pm 0.15 \mathrm{~mm}$ which is similar to those measured for the $\mathrm{Y}$ dimensions. However the range for infiltrated parts increases slightly for larger dimensions, up to $\pm 0.2 \mathrm{~mm}$. Given that the bottom facing surfaces are unsupported during the furnace cycle it is perhaps unsurprising that these measurements are prone to greater variations for larger dimensions as a result of a greater weight of material above the unsupported bottom facing surface. Similar results were obtained for the $\mathrm{Z}_{\text {top-bottom }}$ dimensions measured from the X-face.

Figure 4(c) shows the $\mathrm{Z}_{\text {top-top }}$ dimensions results from the $\mathrm{Y}$-face of the parts in both the green and infiltrated condition. In this case, the green parts show dimensions very close to the 
nominal, with only a very slight increase for larger dimensions. The relatively high accuracy of these dimensions may be explained by the fact that the dimensions are dictated by the easily controlled $\mathrm{Z}$ increments of the platform for each layer. Further, the fact that these green dimensions are smaller than those from the $\mathrm{Z}_{\text {top-bottom }}$ results suggests $\mathrm{Z}$-growth, whereby the heat from the laser penetrates beyond the down facing surface to bond unwanted particles, is occurring on the downward facing surfaces. Additionally, for the geometry used, the down facing surfaces were small and difficult to access during manual powder removal in the green state. The combination of these two factors appears to result in $\mathrm{Z}_{\text {top-bottom }}$ dimensions being $\sim 0.4 \mathrm{~mm}$ greater than $\mathrm{Z}_{\text {top-top }}$ dimensions.

As with the $\mathrm{Y}$ and $\mathrm{Z}_{\text {top-bottom }}$ dimensions in Figure 4(a) and (b), the infiltrated parts in Figure 4(c) show a marked reduction in size compared with nominal. This difference increases with dimension size and corresponds to a linear shrinkage of $\sim 1.3 \%$ during the furnace cycle. Comparing this slope with that from infiltrated parts in Figure 4(b) shows that $\mathrm{Z}_{\text {top-top }}$ is steeper than $\mathrm{Z}_{\text {top-bottom. }}$ This indicates a higher degree of shrinkage in the furnace for $\mathrm{Z}_{\text {top-top }}$ dimensions than top-bottom dimensions. The reason for this greater amount of shrinkage for $\mathrm{Z}_{\text {top-top }}$ dimensions may again be explained by slight slumping of unsupported (downward facing) surfaces. This would result in an increase in the $\mathrm{Z}_{\text {top-bottom }}$ dimensions and corollary less shrinkage.

\section{Breakdown of Error Budget}

For all dimensions, nine measurements of green and infiltrated parts were taken, giving a range of values at both stages. These ranges can be used to indicate the tolerances that could be quoted for the process. For example Figure 4(a) shows that infiltrated parts have a range 
of measurements in Y dimensions of up to $0.3 \mathrm{~mm}$ indicting that a tolerance of $\pm 0.15 \mathrm{~mm}$ in $\mathrm{Y}$ dimensions could be achieved for parts of similar shape and size to the accuracy test part.

Error budget theory tells us that:

$(\mathrm{CAD} \text { to infiltrated tol })^{2}=(\mathrm{CAD} \text { to green tol })^{2}+(\text { green to infiltrated tol })^{2}-$ Eq. 1

Using Eq. 1 we can calculate the tolerances that could be achieved at different stages of the process, namely from CAD to green part and then green part to infiltrated part.

shows the achievable tolerances associated with different stages of the process for the $40 \mathrm{~mm}$ dimension. These were calculated using measured data for infiltrated and green parts and calculated values for "green to infiltrated" from the data presented in Figure 4. This data, shown in italics, represents the tolerance associated with the furnace cycle. This data is also shown graphically in Figure 5.

The data in both Table 2 and Figure 5 shows that for steps in the process (ie from CAD to green or green to infiltrated) the largest loss of tolerance is encountered during the furnace cycle (ie green to infiltrated). This is particularly true for the Z dimensions. Given that the parts were not supported during the furnace cycle this is not surprising and the loss of accuracy may be able to be attributed to the effects of gravity. $\mathrm{Z}_{\text {top-bottom }}$ dimensions appear to be more susceptible to loss of tolerance that $\mathrm{Z}_{\text {top-top }}$ during the furnace stage. This may also be a result of gravity acting on the unsupported downwards facing surfaces during the furnace cycle.

\section{Effect of Build Position on $X$ and Y Dimensions}


Figure 6(a) shows the effect of position within the part bed on the $\mathrm{X}$ dimensions of green parts produced in the SLS machine for nominal dimensions of 20, 50, and 70mm. Since this section investigates the effect of the location of the part within the build bed on the dimension, only data from the green parts is presented. The three lines show that there is a distinct trend of decreasing dimension as parts are built further from the centre. This effect may be a result of a non-uniform temperature distribution in the part bed, which is generally hotter in the centre than at the edges [7]. Consequently, as the laser strikes particles in the centre of the bed the area of powder that reaches a temperature sufficient to bind adjacent particles to each other is larger than when the laser strikes at the edge of corner of the bed. Hence, parts built at the (hotter) centre have larger $\mathrm{X}$ (and Y) dimensions than those at the (cooler) corner or edge of the bed. Figure 6(b) shows the effect of position within the bed on the $\mathrm{Z}_{\text {top-bottom }}$ and $\mathrm{Z}_{\text {top-top }}$ dimensions. As with the $\mathrm{X}$ dimensions, the $\mathrm{Z}_{\text {top-bottom }}$ dimensions were larger for parts at the centre of the bed. This again can be attributed to bed temperature and the phenomenon of Z-growth. However the same trend does not occur for $\mathrm{Z}_{\text {top-top }}$ data. Since the position of the top facing surfaces is controlled by the movement of the part piston, they are insensitive to temperature therefore not dependant on the position within the bed.

\section{Effect of Build Height on X and Y Dimensions}

One of the limitations of the accuracy part used in this work is that large $\mathrm{X}$ and $\mathrm{Y}$ features in this geometry are built before small ones (the reverse is true for $\mathrm{Z}$ features). Having established that position in the part bed affects dimensions, a short study was performed to assess if Z-position has a similar effect. As such, three simple 20mmx20mm square and 100mm tall pillar shown in Figure 1(a) were built on the SLS machine and measured in the green state. $\mathrm{X}$ and $\mathrm{Y}$ dimensions on these parts were measured at different heights from their 
base and are plotted in Figure 7. It is apparent that the size of the pillar is dependant on the point at which is measured, with a gradual increase in dimension with height. Hence, it would be expected that parts built later in a build may have larger dimensions. This again may be attributed to an increase in temperature - in this case the powder in the SLS machine heats up slowly over time, especially in areas where the underlying powder has been sintered. Another factor that may contribute to larger dimensions at the top of the pillars is the possibility that the material that has been exposed to the laser continues to sinter as it descends into the build chamber. Thus layers built at the start will be have more time to continue sintering, resulting in smaller dimensions. As with previous experiments, the data for $\mathrm{X}$ and $\mathrm{Y}$ dimensions are very close.

\section{Summary}

In this paper we have highlighted some of the dimensional accuracy issues in the indirect selective laser sintering of aluminium. The majority of uncertainty (build up of tolerance) in this process occurs during the furnace cycle. This is not surprising as it is also the where the majority of the shrinkage occurs. However, further experiments to assess the influence of such effects such as temperature variations within the furnace and the effect of position in the furnace could be of value.

During the SLS stage the effect of position in X, Y and Z has been shown to affect dimensions of the green (and therefore infiltrated) parts. This has been attributed to temperature variations within the build bed as well as a gradual, overall warming of build volume and continued sintering as the build progresses. Thus, it appears that growth is all directions is a major contributor to the initial variation in dimensions. Nonetheless, the 
dimensional accuracy has been calculated to be similar to that for the investment casting process suggesting the potential to use indirect SLS of aluminium for applications that currently use investment casting especially where geometries are complex and production volumes are low.

\section{Acknowledgements}

The authors would like to thank The UK's Engineering and Physical Sciences Research Council's funding of Loughborough University’s Innovative Manufacturing and Construction Research Centre for funding the exchange element of the this project and The University of Queensland and 3D Systems for assistance with access to facilities and materials to conduct the research.

\section{References}

1. Sercombe, T.B. and G.B. Schaffer, Rapid Manufacturing of Aluminum Components. Science, 2003. 301(5637): p. 1225-1227.

2. Grimm, T., Rapid Prototyping. 2004: Society of Manufacturing Engineers (SME).

3. Pham, D.T., S.S. Dimov, and F. Lacan, Selective laser sintering: Applications and technological capabilities. Proceedings of the IMechE Part B, Journal of Engineering Manufacture,, 1999. 213: p. 435-449.

4. Khaing, M.W., J.Y.H. Fuh, and L. Lu, Direct metal laser sintering for rapid tooling: processing and characterisation of EOS parts. Journal of Materials Processing Technology, 2001. 113(1-3): p. 269-272.

5. ASM handbook Vol 15 - Casting. 1990, Materials Park, Ohio: ASM International. 
6. Sercombe, T.B. and N. Hopkinson, Process Shrinkage and Accuracy during Indirect Laser Sintering of Aluminium. Advanced Engineering Materials, 2006. 8(4): p. 260264.

7. Tontowi, A.E., and Childs T.H.C, Density Prediction of Crystalline Polymer Sintered Parts at Various Powder Bed Temperatures. Rapid Prototyping Journal, 2001. 7(3): p. $180-184$ 
Tab3es

Table 1. Build parameters used

\begin{tabular}{|l|c|}
\hline Laser power $(\mathrm{W})$ & 45 \\
\hline Feed bed temperature $\left({ }^{\circ} \mathrm{C}\right)$ & 70 \\
\hline Build bed temperature $\left({ }^{\circ} \mathrm{C}\right)$ & 121 \\
\hline Layer Thickness $(\mathrm{mm})$ & 0.1 \\
\hline
\end{tabular}

Table 2. Tolerances associated with different stages in the process for $40 \mathrm{~mm}$ dimensions

\begin{tabular}{|c|c|c|c|c|}
\hline & & \multicolumn{3}{|c|}{ Tolerance for $40 \mathrm{~mm}$ dimension $( \pm \mathrm{mm})$} \\
\hline & & $\begin{array}{c}\text { CAD to Green } \\
\text { (measured) }\end{array}$ & $\begin{array}{c}\text { Green to } \\
\text { Infiltrated } \\
\text { (calculated) }\end{array}$ & $\begin{array}{c}\text { CAD to } \\
\text { Infiltrated } \\
\text { (measured) }\end{array}$ \\
\hline & $\mathbf{X}$ & 0.068 & 0.098 & 0.119 \\
\hline & $\mathbf{Y}$ & 0.067 & 0.093 & 0.115 \\
\hline \multirow[t]{2}{*}{$\begin{array}{c}\text { Z dims on } \\
\text { X face }\end{array}$} & $\begin{array}{c}\text { top- } \\
\text { bottom }\end{array}$ & 0.097 & 0.283 & 0.299 \\
\hline & top-top & 0.042 & 0.076 & 0.087 \\
\hline \multirow[t]{2}{*}{$\begin{array}{c}\text { Z dims on } \\
\text { Y face }\end{array}$} & $\begin{array}{c}\text { top- } \\
\text { bottom }\end{array}$ & 0.102 & 0.166 & 0.195 \\
\hline & top-top & 0.064 & 0.127 & 0.142 \\
\hline
\end{tabular}




\section{Figures}

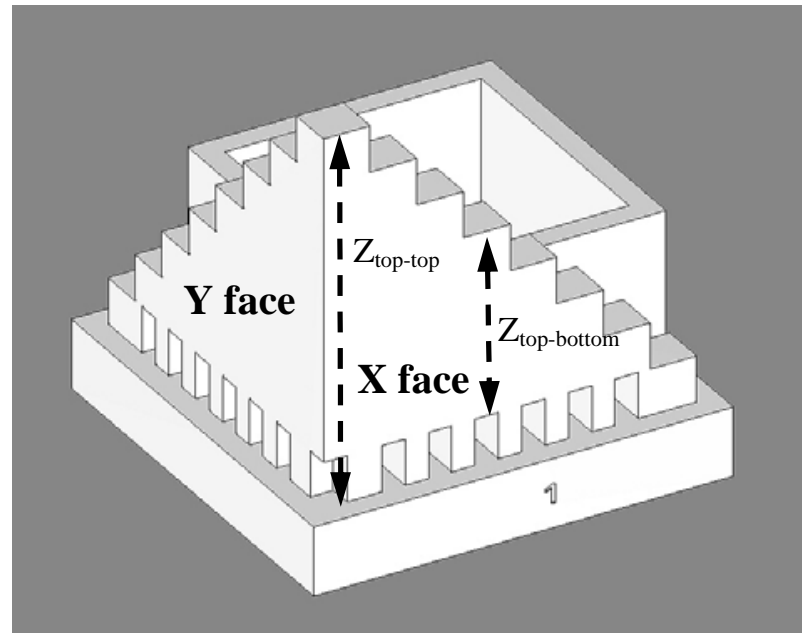

(a)

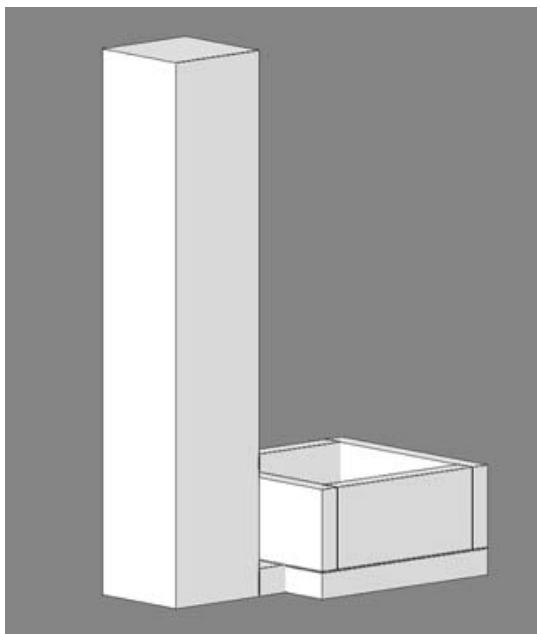

(b)

Figure 1. The geometries used in this work; (a) the accuracy part and (b) pillar.

Dimensions of the accuracy part ranged from 10 to $75 \mathrm{~mm}$ in $X$ and $Y$ and 10 to $80 \mathrm{~mm}$ in

Z. The pillar was $20 \times 20 \times 100 \mathrm{~mm}$.

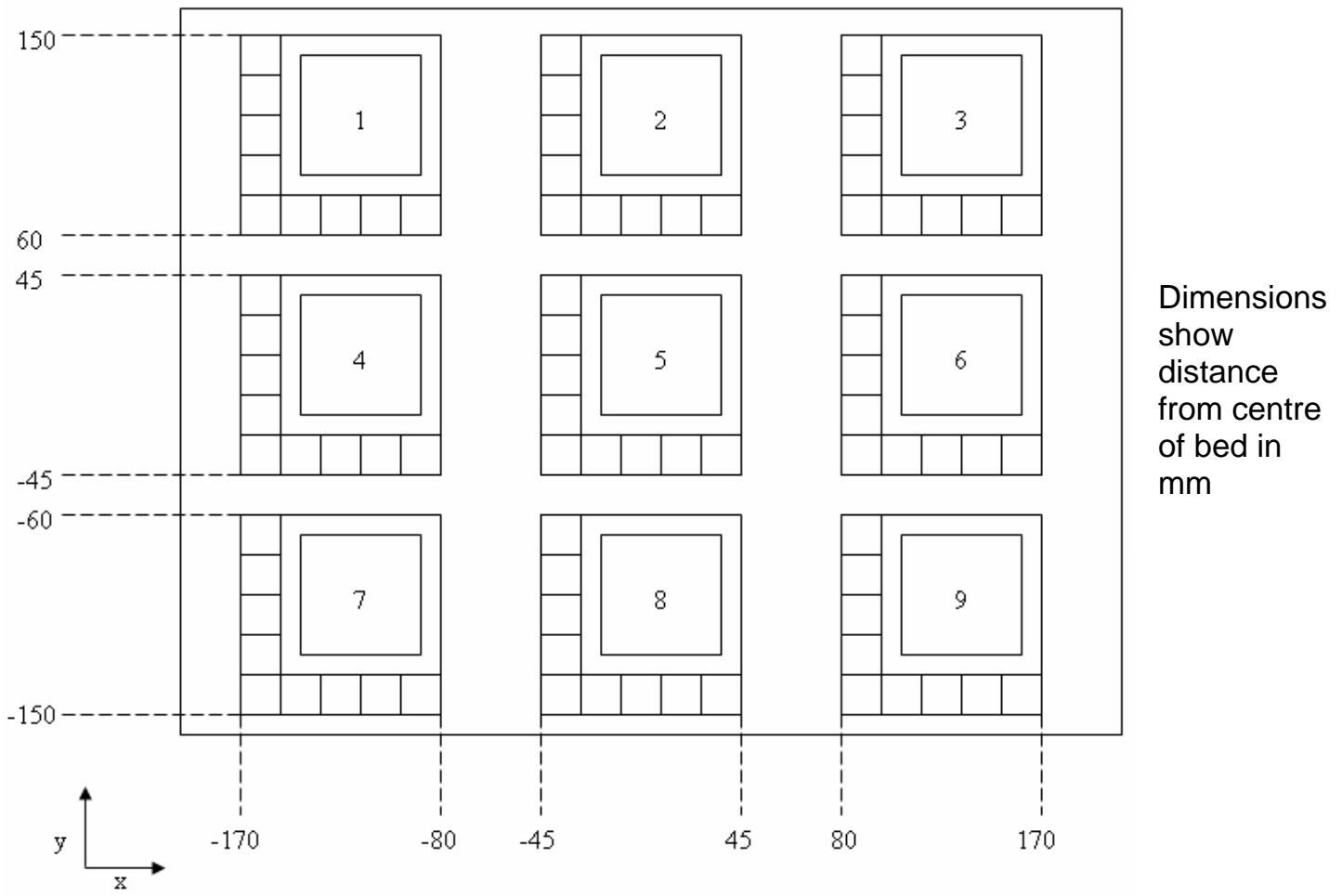

Figure 2. Location of parts in the initial build. 


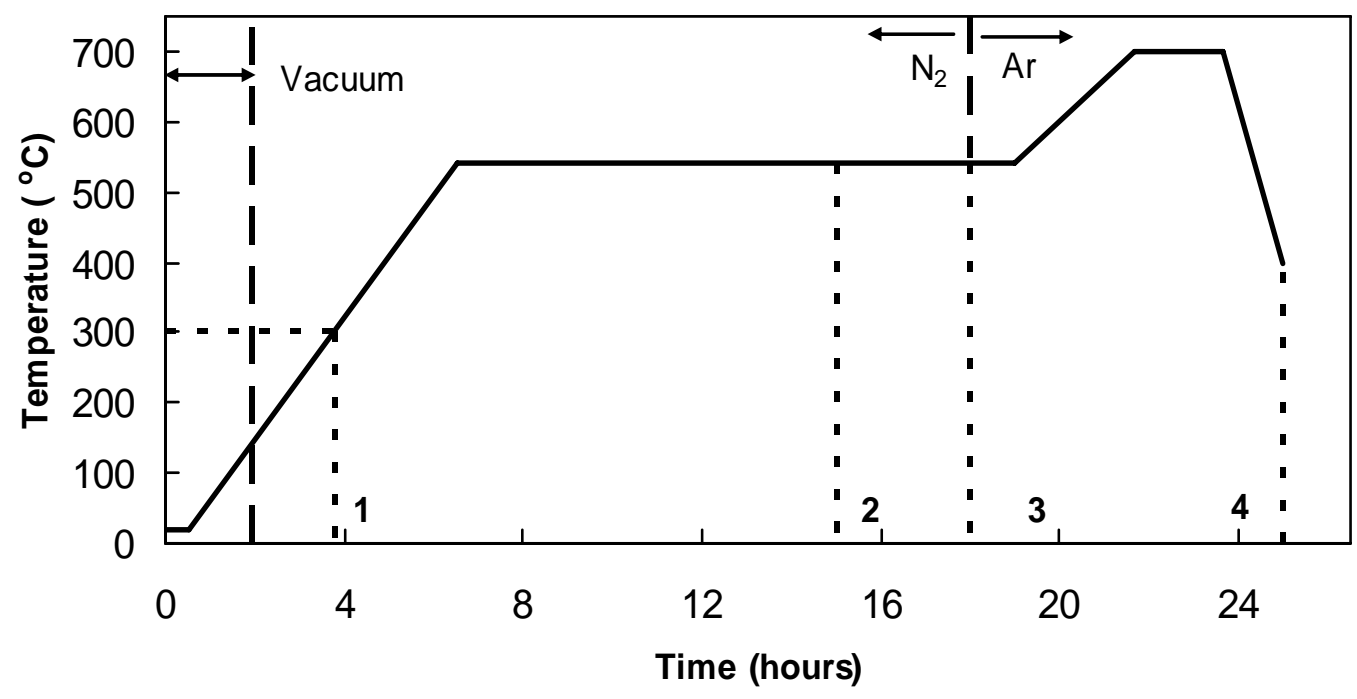

Figure 3. Details of the furnace post-processing stage. 


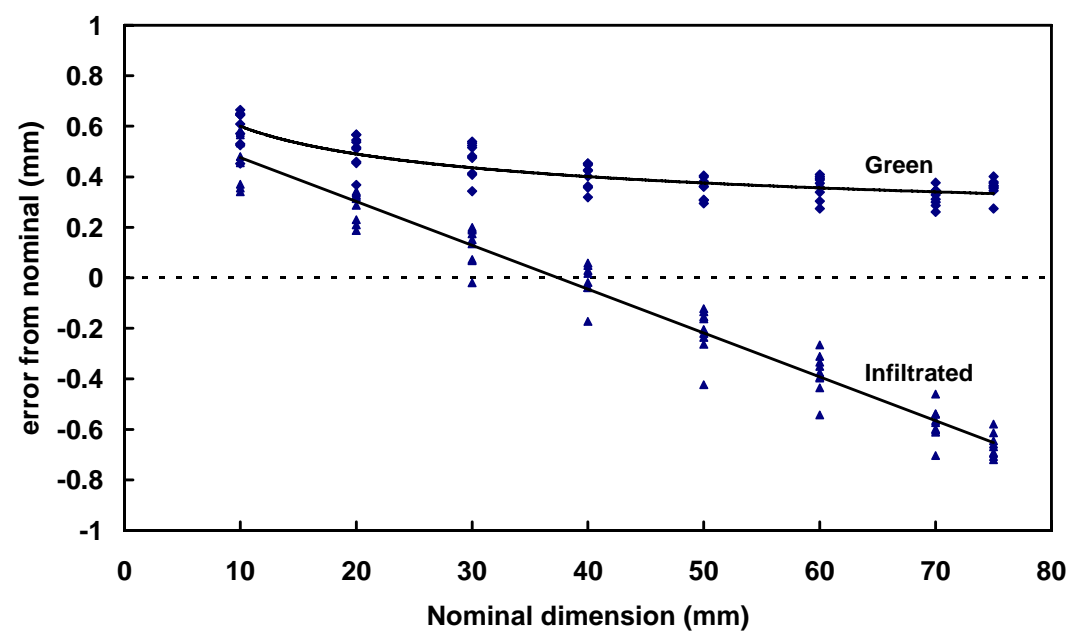

(a)

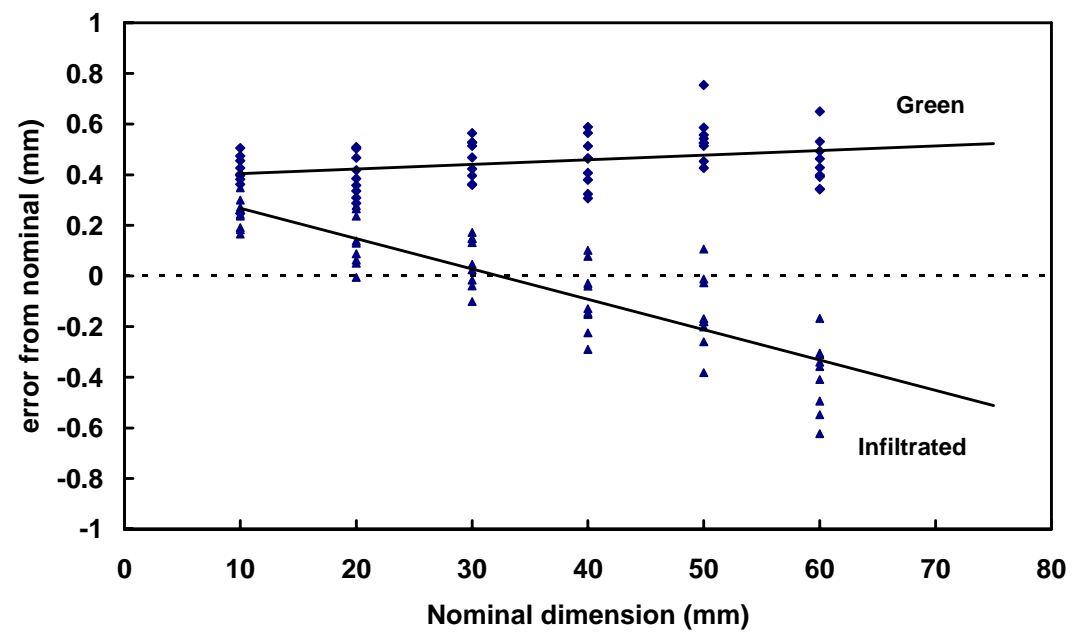

(b)

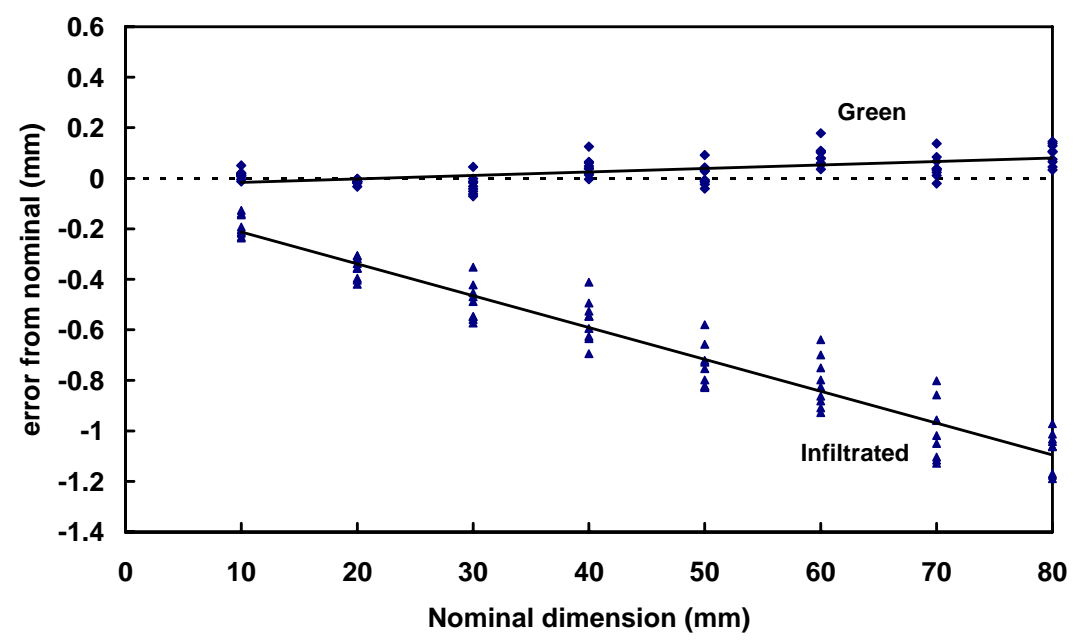

(c)

Figure 4. Green and infiltrated dimensions in the (a) $\mathrm{Y}$, (b) $\mathrm{Zt}_{\text {op-bottom }}$ (from $\mathrm{Y}$-face) and (c) $Z_{\text {top-top }}$ (from $Y$ face). 


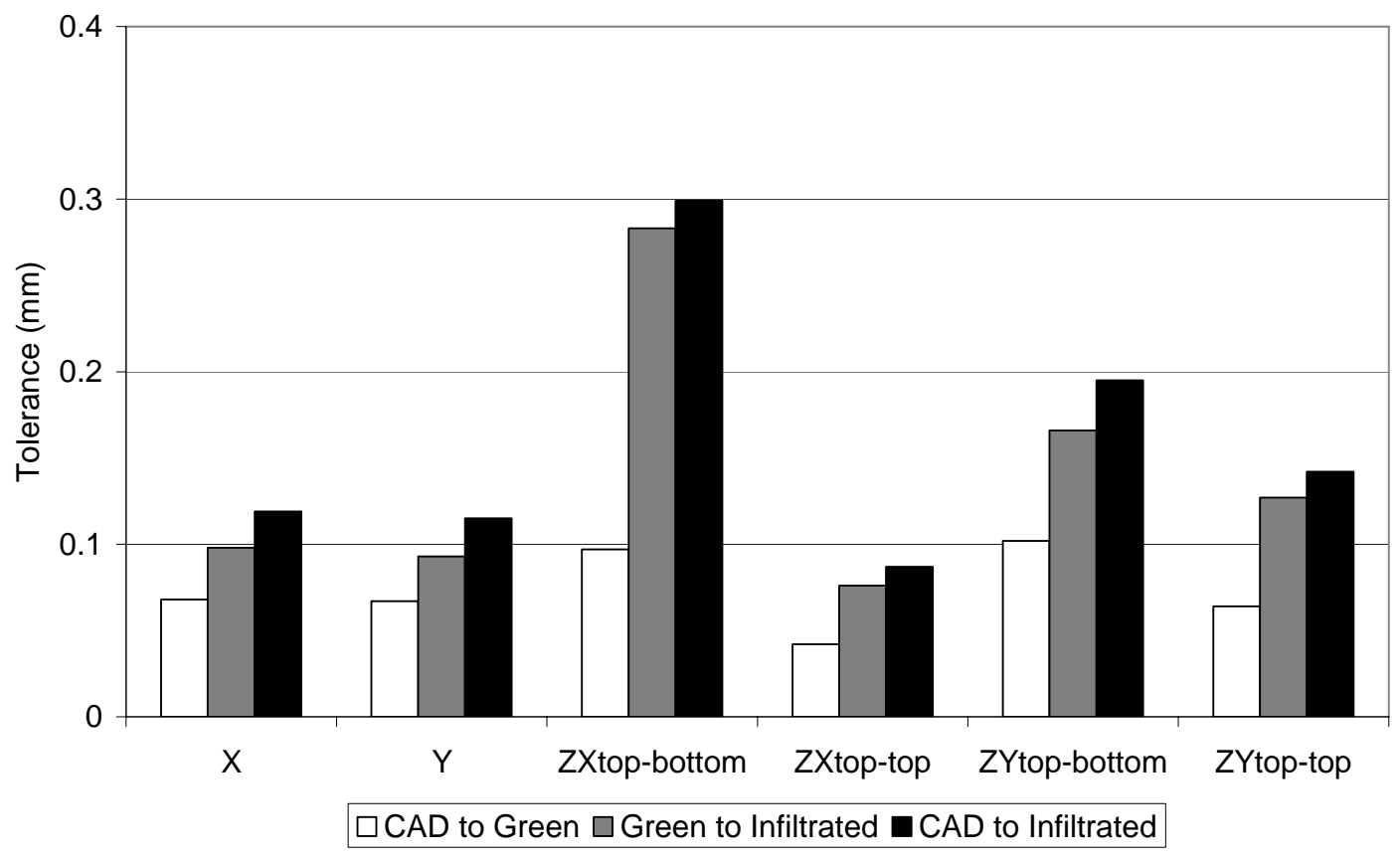

Figure 5. Tolerances associated with different stages in the process for $40 \mathrm{~mm}$ nominal dimensions. 


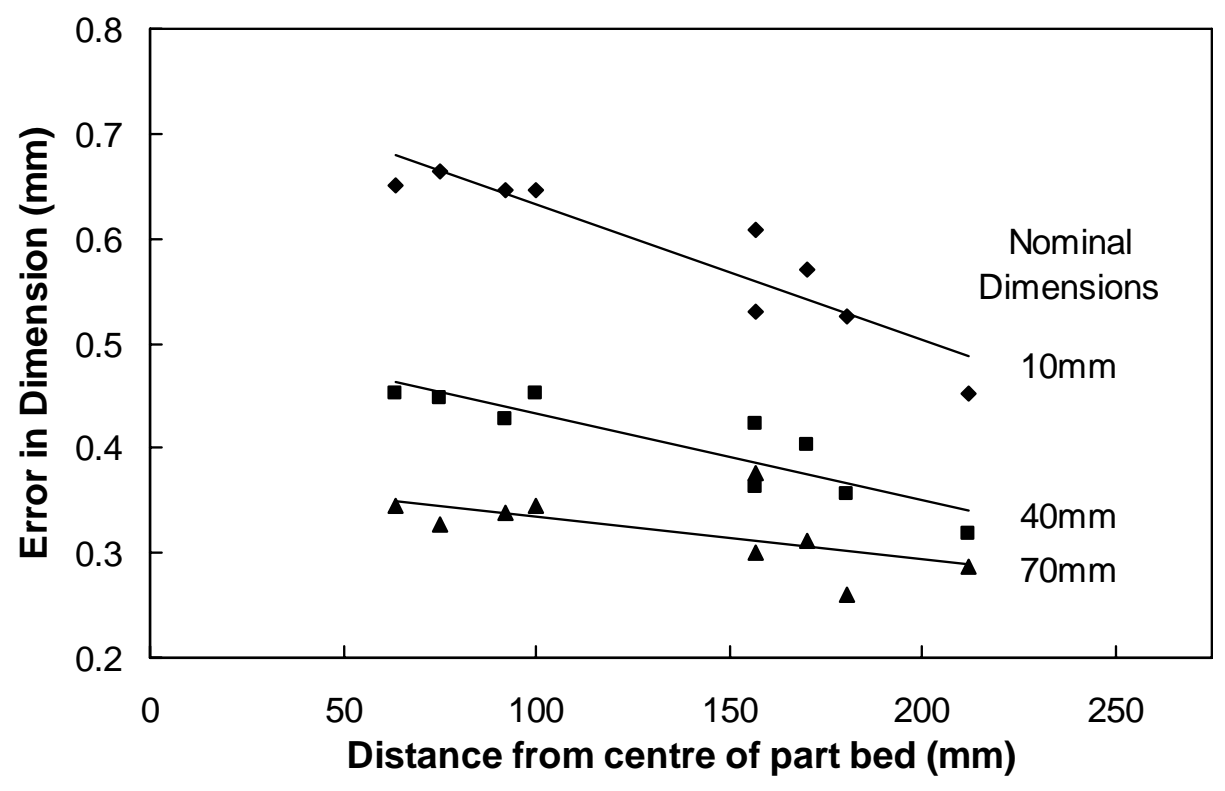

(a)

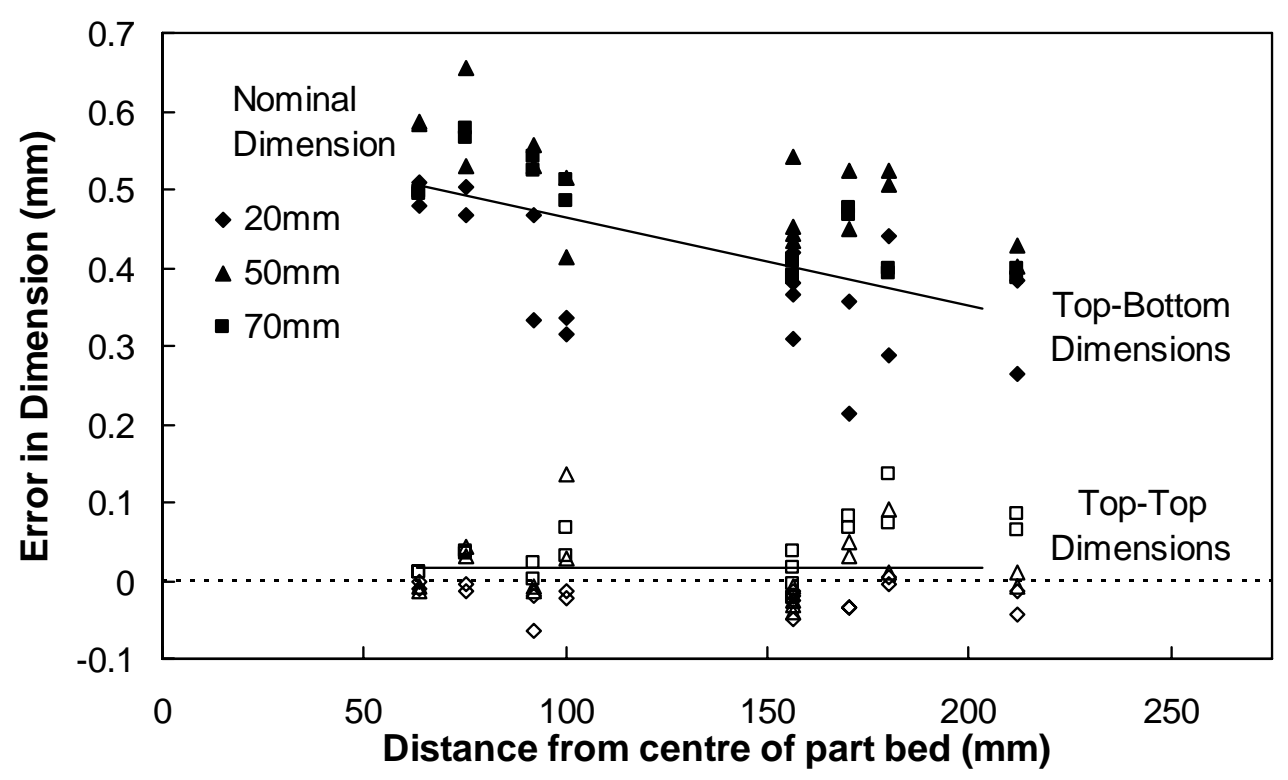

(b)

Figure 6. Effect of bed position on the dimensions of the green part for nominal dimensions of 20,50 and $70 \mathrm{~mm}$ in the (a) $\mathrm{X}$ and (b) $\mathrm{Z}$ directions. 


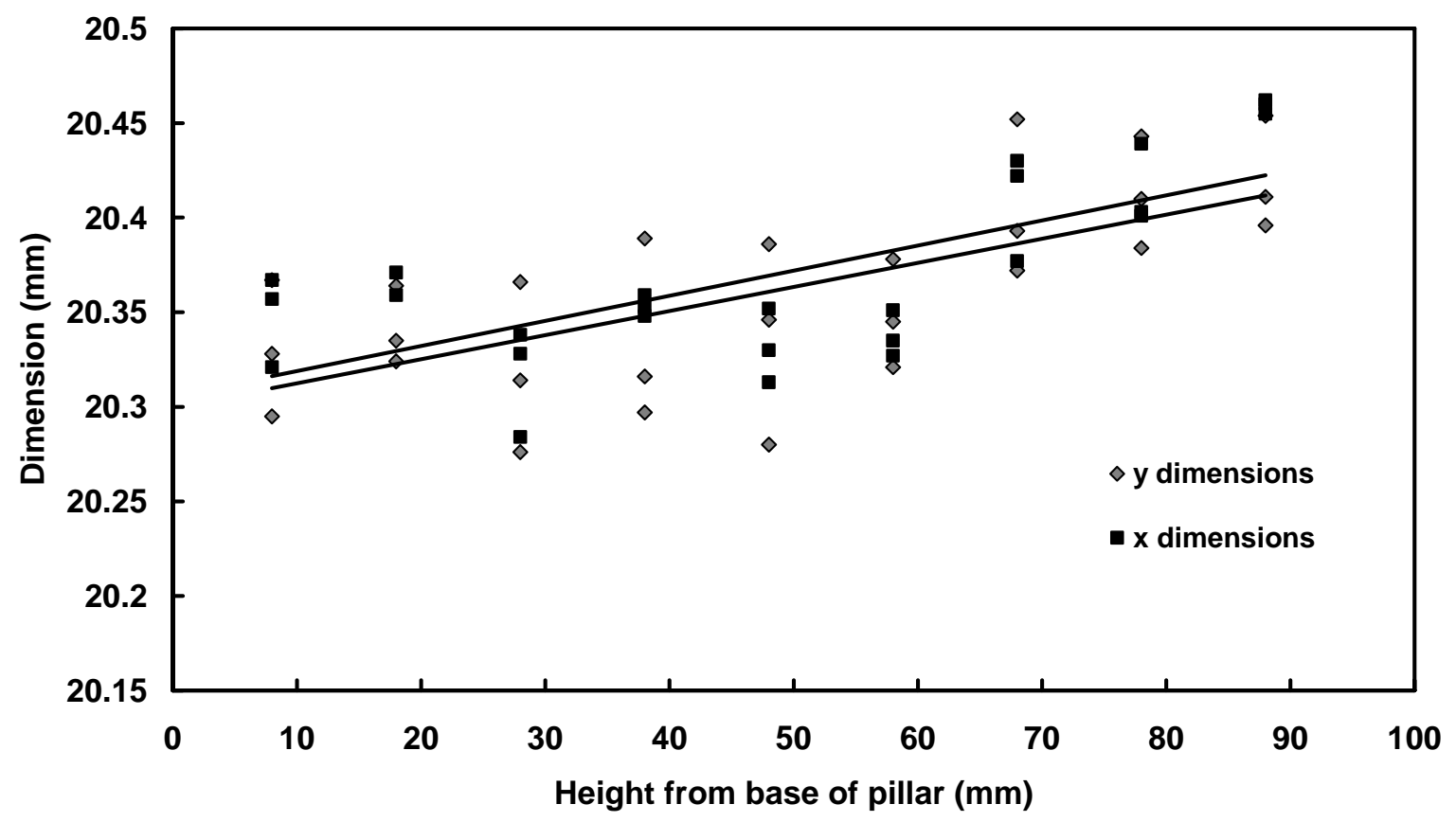

Figure 7. Green dimensions from Pillar parts 